\title{
ELECTROCHEMICAL BEHAVIOR OF POLYCRYSTALLINE COPPER DURING THE ADSORPTION OF CO
}

\author{
J. Salimon* \\ School of Chemical Sciences and Food Technology, \\ Universiti Kebangsaan Malaysia, \\ 43600 Bangi, Selangor DE, Malaysia \\ M. Kalaji \\ Department of Chemistry, University of Wales, \\ Bangor, UK LL57 2UW
}

Received 1 June 2002, Accepted 25 November 2002

\begin{abstract}
The electrochemical properties of electrode copper in carbon monoxide-saturated phosphate buffered solution were investigated. The electrochemistry of copper surface was sufficiently changed after the supporting electrolyte solution was saturated with CO. The hydrogen evolution region was depressed and shifted cathodically due to the adsorption process of $\mathrm{CO}$ on the copper surface in a linear or terminally bonded manner, $\mathrm{Cu}-\mathrm{CO}_{\mathrm{L}}$. The oxidation and the reduction peaks of copper were significantly changed with two couple of redox peaks. This is due to the subsequent formation and the corresponding reduction of copper(I) and the coppercarbon manoxides species. Further changed in electrochemical properties occurred when the electrode surface was polarized at high cathodic potential (-1.4 V) for a period of time (15 min). The hydrogen evolution region was further depressed due to the adsorption of $\mathrm{CO}$ process in multiple bonding sites as adsorbed bridge bonded $\mathrm{CO}, \mathrm{Cu}-\mathrm{CO}_{\mathrm{B}}$ that occurred predominantly.
\end{abstract}

\section{INTRODUCTION}

Depending on the metal surface, carbon monoxide may adsorb either in a molecular form or in a dissociative fashion where in some cases both states coexist on particular surface planes and over specific ranges of temperature. On reactive surfaces of metals (the left-hand side of the periodic table, e.g. Na, Ca, T, rare earth metals) the adsorption is almost invariably dissociative, leading to the formation of adsorbed carbon and oxygen atoms. This reaction thereafter leads to the formation of surface oxide and oxy-carbide compounds ${ }^{1}$. By contrast, on surfaces of metals on the right hand side of the d-block, e.g. $\mathrm{Cu}, \mathrm{Ag}$, the interaction results in the adsorption

*Corresponding author-email: jumat@pkrisc.cc.ukm.my 
of the molecular form. The strength of the interaction between the $\mathrm{CO}$ molecule and the metal is also much weaker, so that the metal-carbon monoxide, M-CO bond may be readily broken and the $\mathrm{CO}$ desorbed from the surface by raising the surface temperature without inducing any dissociation of the molecule. For the majority of the transition metals, however, the nature of the adsorption ( $\mathrm{CO}$ molecular or dissociative) is very sensitive to the surface temperature and surface structure; for example the Miller crystal index plane, the presence of any lower coordination sites such as step and defects sites, and a mixture of a variety of surface structure as in polycrystalline surfaces ${ }^{1,2}$ and the surface pre-treatment ${ }^{3}$.

Although many studies have addressed the adsorption on $\mathrm{Cu}$ of $\mathrm{CO}$ from the gas phase $\mathrm{e}^{4,5,6}$ and from electrolyte solutions ${ }^{7,8,9}$, a concordant conclusion about the exact mechanism for the interaction of $\mathrm{CO}$ with copper surfaces is still unclear, particularly in the latter case and especially as a function of the potential polarization time. The latter is of particular importance in the supposedly electrocatalytic reduction of $\mathrm{CO}_{2}$ on $\mathrm{Cu}$; this process involves the polarization of potential for prolonged periods and involves $\mathrm{CO}$ as an intermediate and product ${ }^{10}$.

In this paper, we report the change of the electrochemical behavior of polycrystalline copper during the adsorption of carbon monoxide in phosphate buffered solution. In situ infrared spectra were also measured to confirm the electrochemical properties change. The Substractively Narmalized Interfacial Fourier Transform Infrared Spectroscopy (SNIFTIRS) techniques were used to detect any interfacial changes during the adsorption of carbon monoxide on the polycrystalline copper surface.

\section{EXPERIMENTAL}

Experimental details in the present study have been reported elsewhere ${ }^{10}$. Electrochemically polished copper electrodes used throughout this work were cathodically protected by applying a negative potential immediately after its immersion into degassed phosphate buffered solution ( $\mathrm{pH}$ 6.8). A cathodic potential, which is close to or at the hydrogen evolution potential was applied for few minutes before the cyclic voltammetry measurements in order to remove any oxides or hydroxides from the surface. Nitrogen gas was bubbled through the solution between the experiments and passed over the electrolyte quiescently during experiments. Carbon monoxide was bubbled for 15 minutes to prepare $\mathrm{CO}$-saturated solutions for both the electrochemistry and the $\mathrm{CO}$ adsorption experiments. The starting applied potential, $\mathrm{E}_{\mathrm{SAP}}$ at high negative potential, $-1.4 \mathrm{~V}$ is immediately applied after its immersion into CO-saturated solution. The IR spectra were measured using a fully evacuated FTIR spectrometer (Bruker IFS-113V) fitted with a mercury-cadmium-telluride (MCT) photoconductive detector. The in situ infrared spectral collection was performed in the positive direction to $0 \mathrm{~V}$ then backs to the initial potential of $-1.4 \mathrm{~V}$. The experimental set up is shown in Figure 1. The same procedure is applied to the polarized surface electrode $\left(\mathrm{E}_{\mathrm{POL}}\right.$ at $\left.-1.4 \mathrm{~V}\right)$ at which the applied potential was hold for 15 minutes before the electrochemical and the infrared spectrum were measured. 


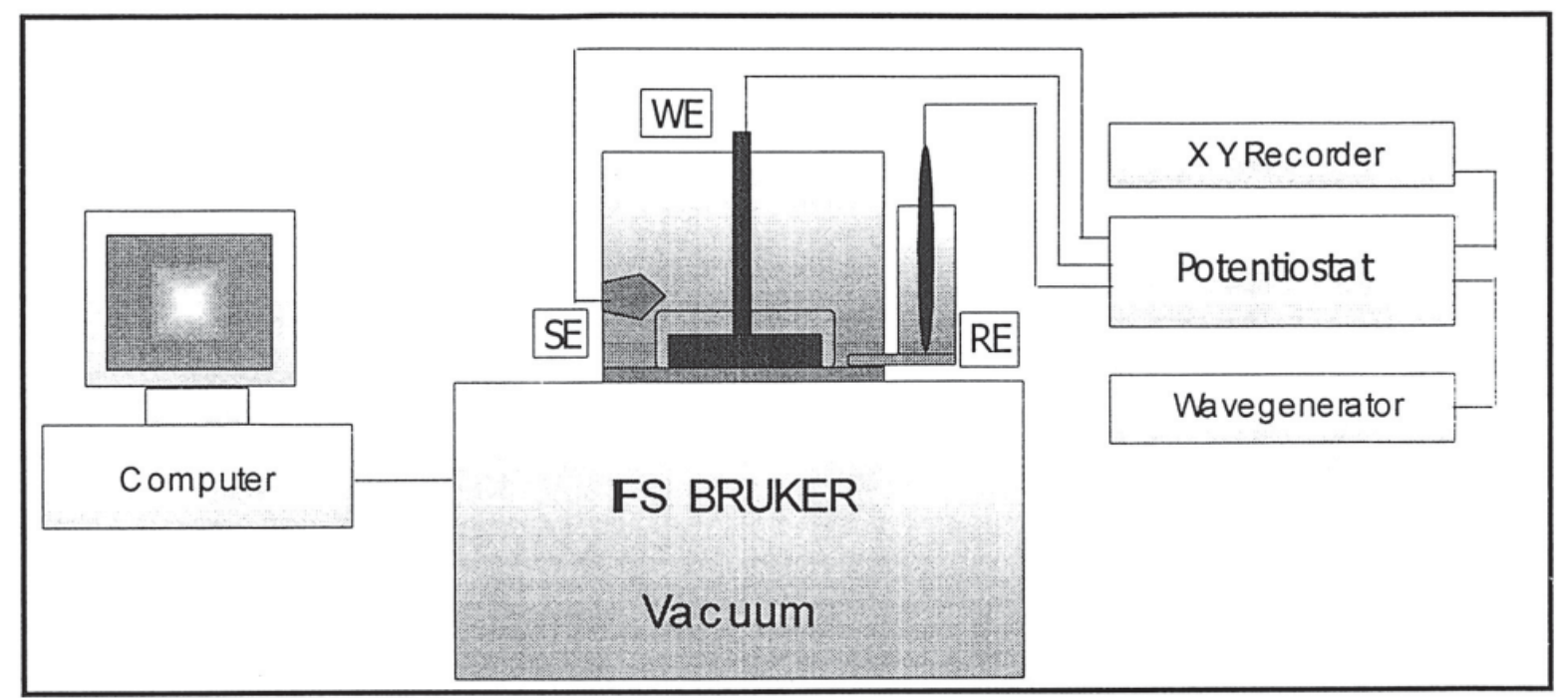

Figure 1 : Schematic diagram of IR in situ measurement

\section{RESULT AND DISCUSSION}

\section{Cyclic voltammetry}

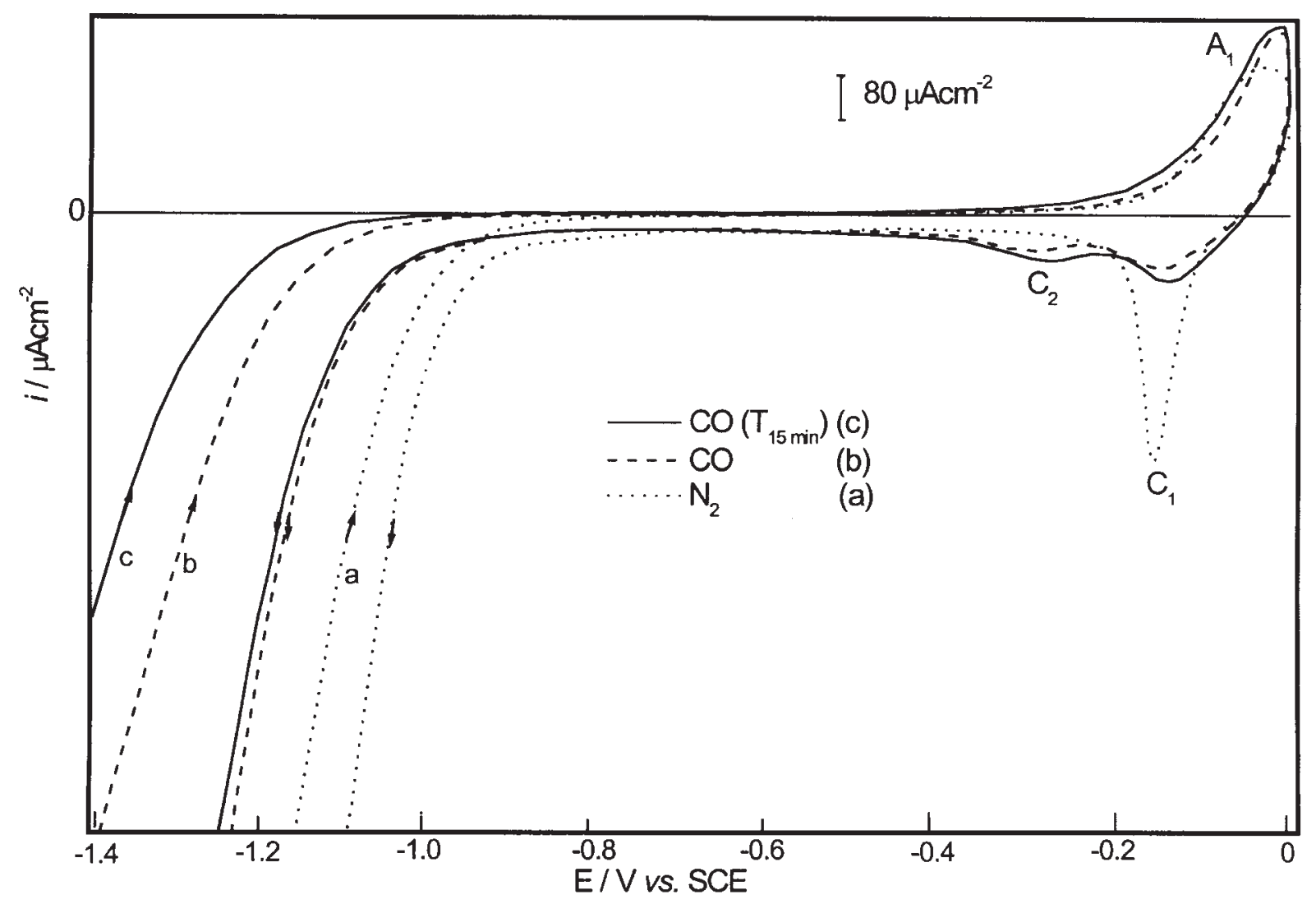

Figure 2 : Voltammogram of copper electrode at $v=0.05 \mathrm{Vs}^{-1}$ in (a) $\mathrm{N}_{2}$ and (b) CO-saturated phosphate buffered solution ( $\mathrm{pH}$ 6.8) at $18^{\circ} \mathrm{C}$ and (c) CO-saturated with polarized electrode at $E_{P O L}=-1.4 \mathrm{~V}$ for $15 \mathrm{~min}$. 
The voltammetric response of $\mathrm{Cu}$ in $\mathrm{N}_{2}$ and $\mathrm{CO}$ saturated phosphate buffer solution at $0.05 \mathrm{~V} / \mathrm{s}$ is shown in Figure 2. The voltammogram are in agreement with the observations at faster sweep rate of $0.1 \mathrm{~V} / \mathrm{s}$ reported in the literature ${ }^{9}$. In $\mathrm{N}_{2}$ saturated solution, the formation and the reduction of copper oxides or/and hydroxides peak, $\mathrm{A}_{1}$ is evident on the forward and reverse sweeps (Fig 2a). On the reverse sweep, the reduction of such species is observed around -0.15 $\mathrm{V}, \mathrm{C}_{1}$. When the solution was saturated with $\mathrm{CO}$, two reduction waves are observed, $\mathrm{C}_{1}$ and $\mathrm{C}_{2}$ at $-0.15 \mathrm{~V}$ and $-0.25 \mathrm{~V}$ respectively. It is plausible to conclude that the reduction of coppercarbon monoxide species occurs at latter peak, $\mathrm{C}_{2}$. However no clear corresponding oxidation peak was obserbed. The onset of hydrogen evolution reaction (HER) region is shifted cathodically upon saturation with $\mathrm{CO}$ (Fig 2b). The data clearly indicate that $\mathrm{CO}$ has a profound influence on the electrochemical behavior of $\mathrm{Cu}$. The hydrogen evolution is depressed cathodically due to the competing reaction between the adsorption of hydrogen and the reaction of $\mathrm{CO}$ on the electrode surface. When the electrode was polarized at $-1.4 \mathrm{~V}$ for $15 \mathrm{~min}$ prior the voltammogram measurement, the onset of hydrogen evolution is further shifted cathodically (Fig 2c). It is due to the effect of the adsorption of $\mathrm{CO}$ on the electrode surface with more negatively charged surface and will be supported in detail spectroscopically.

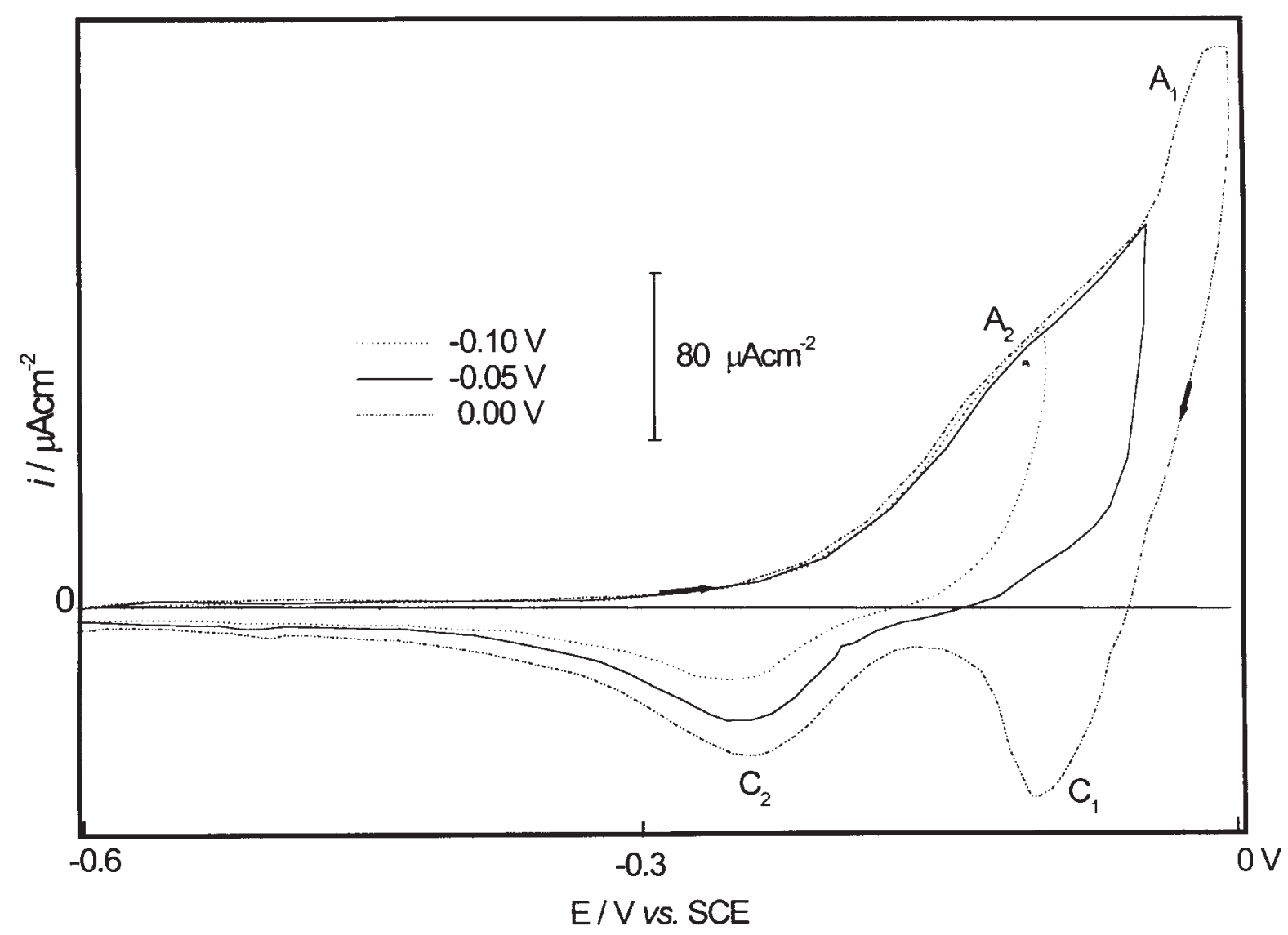

Figure 3 : Voltammogram of copper electrode at $v=0.01 \mathrm{Vs}^{-1}$ in CO-saturated phosphate buffered solution at $18^{\circ} \mathrm{C}$ with different anodic potential limit. 
Figure 3 shows of the effect of positive limit on the voltammetric behavior of $\mathrm{Cu}$ in a $\mathrm{CO}$ saturated solution. At least two redox peaks couples can be observed: $A_{2} / C_{2}$ at $-0.120 /-0.245$ and $\mathrm{A}_{1} / \mathrm{C}_{1}$ at $-0.1 /-0.098 \mathrm{~V}$. The voltammograms were recorded at $10 \mathrm{mV} / \mathrm{s}$, which clearly indicates that the reduction in slow sweep rate results in a better resolution of the redox peaks (compared to Figure 2). The first couple, $\mathrm{A}_{2} / \mathrm{C}_{2}$ is most likely to be associated with the oxidation of $\mathrm{Cu}$ to $\mathrm{Cu}(\mathrm{I})$ and the subsequent formation of the oxides or hydroxide of $\mathrm{Cu}(\mathrm{I})$ and their corresponding reduction. Furthermore the discussion below will show that $\mathrm{CO}$ is also involved and interacted at these potentials.

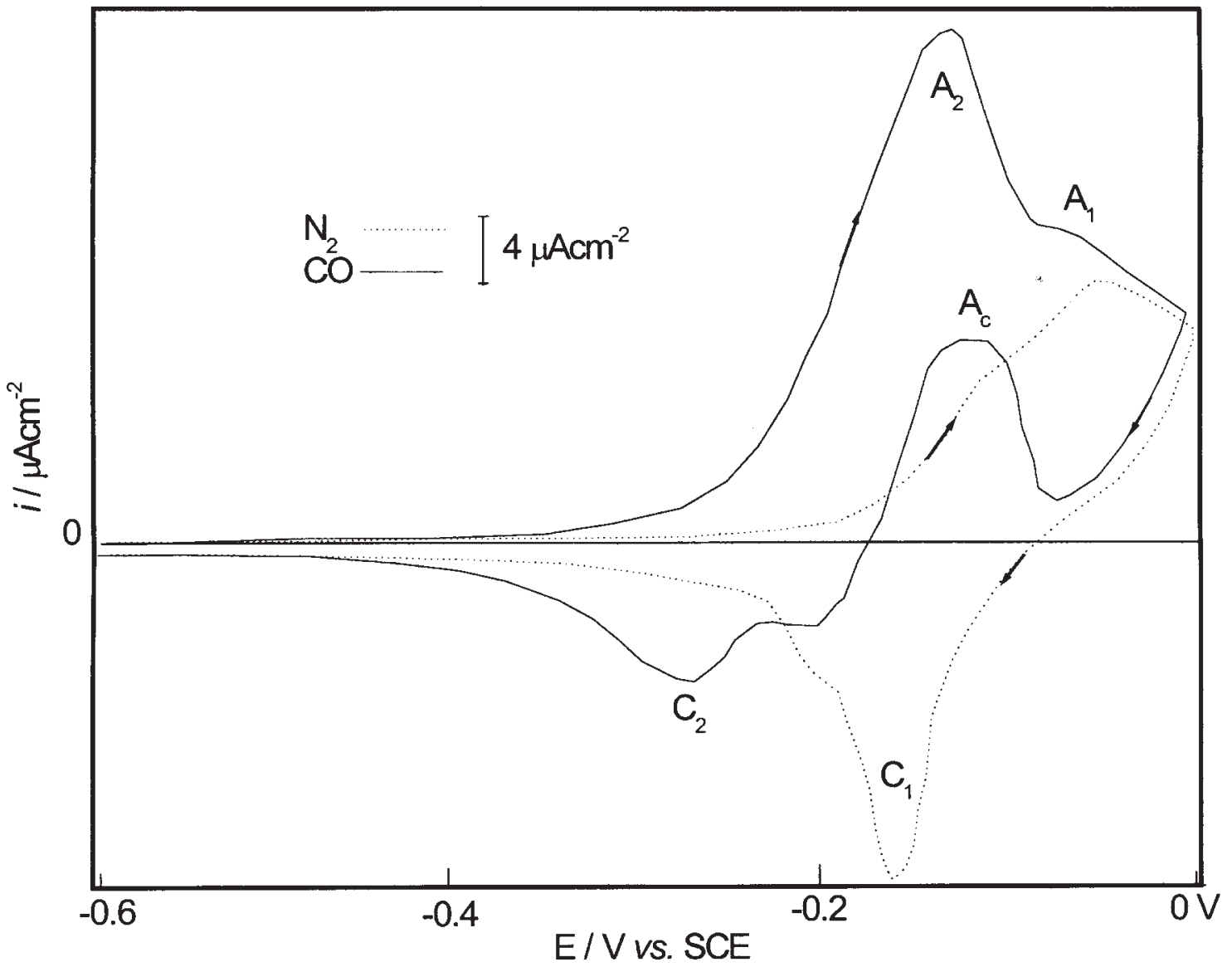

Figure 4 : Voltammogram of copper electrode at $v=0.001 \mathrm{Vs}^{-1}$ in $\mathrm{N}_{2}$ (dot) and CO (solid) saturated phosphate buffered solution (pH 6.8) at $18^{\circ} \mathrm{C}$.

$\mathrm{A}_{1} / \mathrm{C}_{1}$ on the other hand, corresponds to the oxidation of the surface $\mathrm{Cu}(\mathrm{I})$ to $\mathrm{Cu}$ (II) and the reduction back to $\mathrm{Cu}(\mathrm{I})$. Further evidence for this can be obtained when analysing the voltammograms at a very slow sweeps rate, $1 \mathrm{mV} / \mathrm{s}$. Figure 4 shows that the voltammogram of the degassed solution is similar to that obtained at faster sweep rates. However, for the CO saturated solution, the ratio of the anodic current density relative to the $\mathrm{N}_{2}$-saturated solution is much higher at low sweep rates. The charge consumed during the oxidation process at $1 \mathrm{mV} /$ $\mathrm{s}$ when the solution is saturated with $\mathrm{CO}$ is at least 4 times larger than the $\mathrm{N}_{2}$-saturated solution. 
Another interesting feature is that the anodic current is observed during the negative sweep $\left(\mathrm{A}_{\mathrm{c}}\right)$, which was also observed by Hernandez and Kalaji ${ }^{9}$ using mechanically polished electrode. Dragowska et al. ${ }^{11,12}$ observed a similar behavior when copper surfaces were corroded in solutions containing chloride anions. The authors attributed this to the dissolution of the metal. Hernandez and Kalaji ${ }^{9}$ showed using spectroscopic and chronoamperometric measurements that the anodic current on the negatives sweep coincides with the formation of $\mathrm{Cu}(\mathrm{I})$ carboxyl species either by direct reaction of $\mathrm{CO}$ with $\mathrm{Cu}(\mathrm{I})$ or by the reductive reaction of $\mathrm{CO}$ with $\mathrm{CU}(\mathrm{II})$ species. However, the authors failed to observe any adsorbed linear bonded $\mathrm{CO}$ on $\mathrm{Cu}$ in the potential range 0 to $-1.15 \mathrm{~V}$. On the other hand, the present results show that the appearance of adsorbed linear bonded $\mathrm{CO}$ in the potential range more negative than $-1.1 \mathrm{~V}$ (spectrum not shown). Moreover, the results reported previously indicate that the appearance of adsorbed linear bonded $\mathrm{CO}$ during the reduction of $\mathrm{CO}_{2}$ can only be observed if the potential is polarized for a minimum of 10 minutes at potential values more negative than $-1.1 \mathrm{~V}^{10}$. Hence, similar experimental procedure as those utilized previously, were repeated for $\mathrm{CO}$ saturated solutions in order to ascertain the origin of the bands observed during the reduction of $\mathrm{CO}_{2}$.

\section{In situ FTIR}

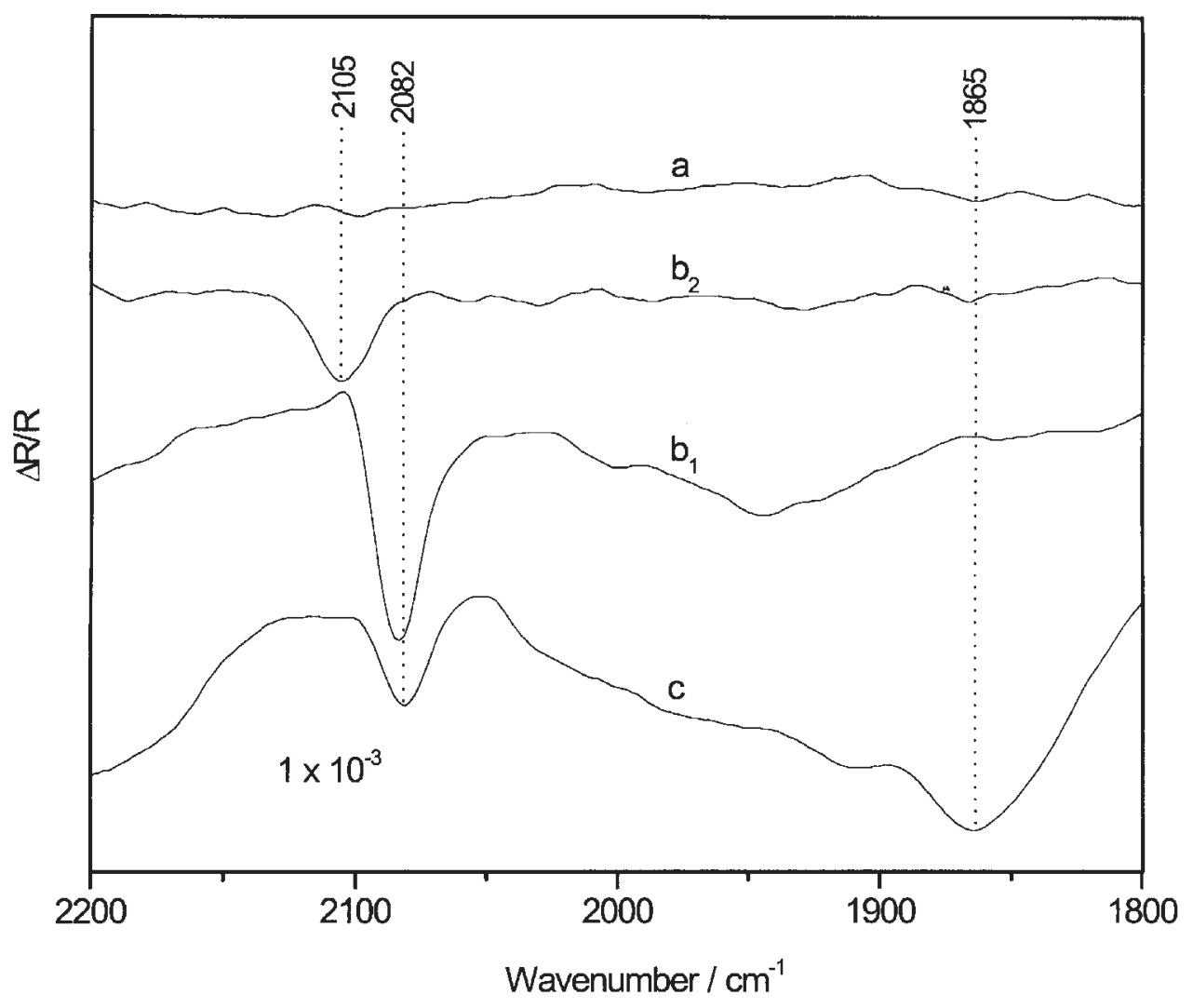

Figure 5 : SNIFTIR spectra of copper electrode for the same experimental condition as in Fig. 1. Spectrum (a) for $\mathrm{N}_{2}$-saturated, $\mathrm{b}_{1}$ and $\mathrm{b}_{2}$ (at $-0.1 \mathrm{~V}$ ) for CO-saturated and $\mathrm{c}$ for $\mathrm{CO}$-saturated with polarized electrode at $\mathrm{E}_{\mathrm{pol}}=-1.4 \mathrm{~V}$ for $15 \mathrm{~min}$ at $18^{\circ} \mathrm{C}$ in phosphate buffered solution ( $\mathrm{pH} 6.8)$. Spectra shown at $-1.3 \mathrm{~V}\left(\mathrm{a}, \mathrm{b}_{1}, \mathrm{c}\right)$ and $-0.1 \mathrm{~V}$ $\left(b_{2}\right)$; normalized to spectrum obtained at $-0.4 \mathrm{~V}$ (reverse sweep). 
Figure 5 shows the SNIFTIRS measurement for the same experimental condition as shown in Figure 2. The spectrum was calculated by subtracting the spectrum obtained at $-1.3 \mathrm{~V}$ (reference spectrum at potential of $-0.4 \mathrm{~V}, \mathrm{E}_{\mathrm{REF}}=-0.4 \mathrm{~V}$ of reverse sweep) in each set, from the spectrum collected at $\mathrm{E}_{\mathrm{SAP}}$. In CO-saturated solution $\left(b_{1}\right)$, a monopolar band is observed at $2082 \mathrm{~cm}^{-1}$ that occasionally shifts with potential (not shown). This band is neither observed in $\mathrm{N}_{2}$-saturated solution under the same conditions (a) nor in CO-saturated solution when s-polarized radiation was used. From the surface selection rules, it is clear that the species responsible for this absorption is an adsorbed species and as expected it is assigned to linear bonded $\mathrm{CO}, \mathrm{Cu}$ $\mathrm{CO}_{\mathrm{L}}$. The band position is in agreement with $\mathrm{vC}=\mathrm{O}$ stretching frequency of adsorbed $\mathrm{CO}$ on $\mathrm{Cu}$, which lies in the frequency range of 1990 to $2100 \mathrm{~cm}^{-1}$ for linearly adsorbed $\mathrm{CO}$ on thin $\mathrm{Cu}$ films $7,13,14$ and on $\mathrm{Cu}(100)$ at 2070 to $2090 \mathrm{~cm}^{-1}$ 2,15. The adsorption of $\mathrm{CO}$ must be responsible for the observed negative shifts in the onset of HER as indicated by voltammogram in Figure 2. At anodic potentials of $-0.1 \mathrm{~V}$, a new band appears at $2105 \mathrm{~cm}^{-1}$ (spectrum $\mathrm{b}_{2}$ ) which as previously reported, is due to the formation of copper (I)-carbonyl, $\mathrm{Cu}(\mathrm{I})-\mathrm{CO}$, as the copper surface is oxidized. It indicates that as copper(I) forms, it reacts with $\mathrm{CO}$ to form $\mathrm{Cu}(\mathrm{I})$ $\mathrm{CO}$. This is consistent with the same observation obtained when the reduction of $\mathrm{CO}_{2}$ occurs in the $\mathrm{CO}_{2}$-saturated solution ${ }^{10}$.

An interesting observation when the electrode surface was polarized at $-1.4 \mathrm{~V}$ for 15 minutes in the CO-saturated solution. The same band at $2082 \mathrm{~cm}^{-1}$ appears for the linearly bonded adsorbed $\mathrm{CO}$ with less band intensity. Another negative band at $1865 \mathrm{~cm}^{-1}$ appears at lower wave number (spectrum c). The band shows shifting in wave number as the potential is changed (not shown). The latter band was briefly discussed previously and its assignment is in agreement with values reported in the literature ${ }^{9,16-18}$. The appearance of a new band at lower wave number is due to the formation of adsorbed bridge bonded carbon monoxide ${ }^{2}, \mathrm{Cu}-\mathrm{CO}_{\mathrm{B}}$. The results show that the adsorption of $\mathrm{CO}$ depends on the state of the copper surface either without or with polarization process. The results can be simplified as follows where $\mathrm{Cu}-\mathrm{CO}_{\mathrm{L}}$ appears immediately after the electrode surface is applied with the starting applied potential, $\mathrm{E}_{\mathrm{SAP}}$ at high negative potential. Adsorbed bridge bonded $\mathrm{CO}, \mathrm{Cu}-\mathrm{CO}_{\mathrm{B}}$ on the other hand, appears as a time function of polarization potential, $\mathrm{E}_{\mathrm{POL}}$. A reduction in band intensity of $\mathrm{Cu}-\mathrm{CO}_{\mathrm{L}}$ during the polarization of the electrode surface seems to have a correlation with the appearance of $\mathrm{Cu}$ $\mathrm{CO}_{\mathrm{B}}$ band. This will be discuss in detail elsewhere.

\section{CONCLUSION}

The cyclic voltametric results show that the electrochemical behavior of copper surface is changed when the solution is saturated with CO. The hydrogen evolution region is shifted cathodically and the charge consume during the oxidation of copper increases. This is due to the adsorption of $\mathrm{CO}$ on the copper surface $\left(\mathrm{Cu}-\mathrm{CO}_{\mathrm{L}}\right)$. Further dramatic change in electrochemical behavior occurs when the copper surface is polarized at high cathodic potential for a period of time. Through the polarization process the adsorption of $\mathrm{CO}$ on polycrystalline occurs at two binding sites, linearly bonded $\mathrm{CO}$ and bridge bonded $\mathrm{CO}$. It suggests that the main problem need to overcome prior the $\mathrm{CO}$ adsorption on the electrode surface is the removal of the pre- 
adsorbed anions, especially hydroxide from the surface due its competing reaction with the adsorption of CO. Polarizing the electrode surface at high cathodic potential is one way of removing the pre-adsorbed anions. No higher 3-fold hollow multiple bonded CO was observed under the experimental conditions.

\section{ACKNOWLEDGMENT}

The authors would like to thank UKM-Malaysia for financial support and Dr. R.J. Nichol (U. Liverpool, UK) for useful discussions.

\section{REFERENCES}

1. Hollins, P and Pritchard, J. (1983), Surf. Sci., 134, p. 91.

2. Hayden, B.E, Kretzschmar, K. and Bradshaw, A.M. (1985), Surf. Sci., 155, p. 553.

3. Hori, Y., Murata, A., Yoshinami, Y. (1991), J. Chem. Soc. Faraday Trans., 87, p. 125.

4. Hayden, B.E, Bradshaw, A.W. (1983), Surf. Sci., 125, p. 787.

5. Hollins, P., Davies, K.J. and Pritchard, J. (1984), Surf. Sci., 138, p. 75.

6. Hayden, B.E., Prince, K., Woodruff, D.P. and Bradshaw, A.M (1983), Surf. Sci., 133, p. 589.

7. Hori, Y., Koga, O., Yamazuki, H. and Matsuo, T. (1995) Electrochim. Acta, 40, p. 2617.

8. Hori, Y., Koga, O., Watanabe, Y., Matsumo, T. (1998), Electrochim. Acta, 44, p. 1389.

9. Hernandez, R and Kalaji, M. (1997), J. Electroanal. Chem., 434, p. 209.

10. Salimon, J. and Kalaji, M. (2002), Malay, J. Anal. Sci., in press.

11. Dogrowska, M., Brossard, L. and Menard, H. (1992), J. Electrochem. Soc.,139, p. 39.

12. Dogrowska, M., Brossard, L. and Menard, H. (1992), J. Electrochem. Soc., 139, p. 2789.

13. Hori, Y., Murata, A., Tsukamoto, T., Wakebe, H., Koga, O and Yamazaki, H (1994), Electrochim. Acta., 39, p. 2495.

14. Pritchard, J. and Sims, M.L. (1970), Trans. Farady. Soc., 66, p. 427.

15. Horn, K., Hussian, M. and Pritchard, J. (1977), Surf. Sci., 63, p. 244.; Tang, C., Zou, S.Z., Chang, S.C. and Weaver, M.J. (1999), J. Electoral. Chem., 467, p. 92.

16. Kitamura, K., Takahashi, M. and Ito, M. (1988), J. Phys. Chem., 92, p. 3320.

17. Truong, C.M., Rodriguez, J.A. and Goodman, D.W. (1992), Surf. Sci. Lett., 271 L, p. 385.

18. Raval, R., Parker, S.F., Pemble, M.E., Hollins, P., Pritchard, J. and Chesters, M.A. (1988), Surf. Sci., 203, p. 353. 